\title{
UPAYA MENGATASI PELANGGARAN TATA TERTIB SEKOLAH MELALUI KONSELING INDIVIDU TEKNIK RASIONAL EMOTIF BEHAVIOR PADA SISWA KELAS XI IPS 2 SMA NEGERI 2 PACITAN TAHUN PELAJARAN 2019/2020
}

\author{
Dwi Noviarini \\ SMA Negeri 2 Pacitan \\ dwinoviarini1981@gmail.com \\ Trikayani \\ SMK Nuris Jember \\ trikayanimoser@gmail.com \\ Mudho Eko Prambudiono \\ SMK Ma'arif Sudimoro Pacitan \\ mudhotaruno@gmail.com \\ Akhmad Baihaqi, S.Psi. \\ SMK Walisongo 2 Gempol Pasuruan \\ mubah100@gmail.com \\ Riyanti Utami \\ SMA Negeri 1 Kalianget \\ riyantiutami22@gmail.com
}

\begin{abstract}
Abstrak
Kegiatan penelitian memiliki tujuan untuk mengatasi Pelanggaran tata tertib sekolah melalui efektifitas konseling individu dengan teknik Rasional Emotif Behavior pada siswa kelas XI IPS 2 SMA Negeri 2 Pacitan. Adapun yang merupakan subyek dari kegiatan penelitian Tindakan Kelas ini adalah siswa kelas XI IPS 2 SMA Negeri 2 Pacitan, dengan jumlah siswa 32 anak adapun yang dijadikan klien dalam Konseling individu mengunankan teknik Rational Emotif Behavior sebanyak 10 siswa. Hasil Analsisi siklus 1 sebelum diadakan konseling individu yaitu sebesar $80 \%$ dan hasil siklus 2 setelah diadakan konseling individu sebesar 60\%. Hal ini menunjukkan bahwa ada peningkatan kearah positif. Meskipun selisih hasil tes pertama dan kedua hanya $20 \%$. Terdapat keterangan bahwa Semakin tinggi skor yang diperoleh maka, semakin rendah perilaku melanggar tata tertib sekolah yang dilakukan oleh siswa 10 siswa/konseli yang dijadikan observasi secara langsung yang dilakukan di kelas .

Kata Kunci: tata tertib, konseling individu teknik rasional emotif behaviour
\end{abstract}

\begin{abstract}
This research activity aims to overcomes violations of school discipline through the effectiveness of individual counseling with the Rational Emotional Behavior technique for class XI IPS 2 SMA Negeri 2 Pacitan. The subject of this Classroom Action research activity are students of class XI IPS 2 SMA Negeri 2 Pacitan, with a total of 32 students who are clients in individual counseling using the Rational Emotive Behavior thechnique is 10 students. The results of the analysis of 1st cycle before individual counseling were held is $80 \%$, and the result of the $2^{\text {nd }}$ cycle after individual counseling were $60 \%$. This shows that there is an increase in a positive direction. Although the difference between the first and second test results is only 20\%. There is information that the higher the score obtained, the lower the behavior of violating school rules by 10 students/counselees which is used as direct observations made in class.
\end{abstract}

Keywords: discipline, individual counselling techniques, rational emotive behavior 


\section{LATAR BELAKANG}

Sekolah merupakan tempat pendidikan formal yang mempunyai peranan penting yaitu menciptakan kepribadian yang mantap dan mandiri. Hal itu dapat berhasil apabila guru dapat mendorong dan mengarahkan anak didik dalam mengembangkan nilai - nilai sosial yang berlaku di sekolah maupun di masyarakat. Untuk mencapai hal tersebut, kedisiplinan dan tata tertib sangat menentukan dalam pembentukan perilaku siswa agar siswa disiplin melaksanakan tata tertib yang diharapkan oleh sekolah untuk mencapai tujuan pendidikan nasional. Pentingnya pendidikan di sekolah membuat seluruh komponen yang ada di sekolah menyadari arti pentingnya tata tertib di sekolah. Tata tertib ini sangat bermanfaat untuk mengajarkan kedisiplinan kepada siswa. Meskipun begitu masih banyak siswa yang melakukan pelanggaran terhadap tata tertib sekolah. Elizabeth B. Hurlock (1993) mengatakan bahwa disiplih merupakan cara masyarakat mengajarkan anak berperilaku moral yang disetujui kelompok.

Sesuai pengamatan di lapangan banyak siswa kelas XI IPS 2 SMA Negeri 2 Pacitan yang sering melanggar tata tertib sekolah, misalnya memakai seragam sekolah dengan atribut yang tidak lengkap, baju tidak dimasukkan, terlambat masuk kelas, tidak mengikuti upacara tanpa ijin, tidak mengerjakan tugas atau PR dan membolos. Perilaku-perilaku tersebut merupakan gejala pelanggaran yang dilakukan pada siswa kelas XI IPS 2 SMA Negeri 2 Pacitan terhadap tata tertib sekolah, dengan kata lain siswa tersebut termasuk tidak disiplin. Apabila pelanggaran tersebut tidak segera diatasi dikhawatirkan dapat merusak nama baik sekolah dan dapat menghambat proses belajar mengajar yang berdampak pada menurunnya prestasi siswa dan terganggunya sosialisasi guru dengan siswa.

Adanya layanan bimbingan dan koseling di sekolah diharapkan berfungsi membantu mengembangkan potensi peserta didik agar menjadi manusia yang beriman dan bertakwa kepada Tuhan Yang Maha Esa, berakhlak mulia, sehat, berilmu, cakap, kreatif, mandiri. Guru dan guru BK sebagai pendidik, yang menjadi contoh dan panutan, dan identifikasi bagi para peserta didik, dan lingkungannya. Oleh karena itu pada siswa kelas XI IPS 2 SMA Negeri 2 Pacitan guru perlu memiliki standar kualitas pribadi bagi anak didiknya, yang mencangkup tanggung jawab, guru harus mengetahui, serta memahami nilai, norma moral, dan sosial, serta berusaha berperilaku dan berbuat sesuai dengan nilai dan norma tersebut.

Guru dan konselor selain berkewajiban mengajar siswa di kelas juga dituntut untuk membantu membimbing siswa yang sering melanggar tata tertib sekolah menjadi siswa yang mematuhi tata tertib sekolah. Pemberian bimbingan terhadap siswa dibutuhkan pengelolaan yang baik yang meliputi perencanaan, pelaksanaan, dan evaluasi dari pelaksanaan bimbingan dan konseling yang baik dan matang. Prayitno (1985 : 15) menjelaskan masalah adalah sessuatu yang tidak disukai adannya, menimbulkan kesulitan bagi dirinya sendiri dan orang lain dan perlu dihilangkan. Agar dapat memberikan bantuan yang tepat guru perlu mengenali 
dan memahami siswanya yang sering melanggar tata tertib sekolah. Pengenalan dan pemahaman akan lebih mendalam bila dilakukan dengan penelitian.

Penegakkan tata tertib sekolah harus dimulai dari komponen sekolah itu sendiri, yaitu kepala sekolah, guru, semua siswa dan unsur masyarakat sebagai salah satu penentu kebijakakan sekolah. Sebagai lembaga pendidikan, sekolah mempunyai fungsi dan tugas edukatif yang meliputi tiga dimensi mendidik yang menghasilkan etika dan pergaulan, mengajar, menghasilkan kecerdasan dan melatih menghasilkan keterampilan.

Perilaku diatas dapat disimpulkan bahwa perilaku melanggar disiplin dan tata tertib sekolah pada siswa kelas XI IPS 2 SMA Negeri 2 Pacitan dianggap sebagai perilaku menyimpang dan merupakan masalah. Disiplin dan tata tertib sekolah merupakan salah satu upaya untuk membentuk pribadi anak yang mandiri dan bertanggung jawab. Guru bersama konselor selain berkewajiban melakukan pembelajaran terhadap siswa, juga dituntut untuk membantu membimbing siswa yang sering melanggar tata tertib menjadi siswa yang mematuhi tata tertib sekolah. Pada siswa yang melanggar tata tertib sekolah maka dapat di coba untuk melakukan konseling individu menggunakan teknik konseling Rational Emotif Behavior.

Dimana dalam terapi ini diharapkan siswa yang melanggar tata tertib sekolah dapat mengubah pemikirannya dari yang irasional menjadi rasional, sehingga ia mampu mencoba untuk membenahi diri baik dari sikap maupun tingkah laku dalam seharihari. Dalam teknik yang digunakan dapat melatih, mendorong, dan membiasakan klien untuk secara terus-menerus menyesuaikan dirinya dengan tingkah laku yang diinginkan. Latihan-latihan yang diberikan lebih bersifat pendisiplinan dari klien.

Pada dasarnya dalam hal ini akan dititik beratkan dalam upaya membantu mengatasi siswa yang melanggar tata tertib sekolah melalui layanan konseling individu dengan teknik konseling Rational Emotif Behavior yang diharapkan akan lebih mengena dan terfokus kepada diri individu. Oleh karena itu, penulis akan membahas suatu permasalahan yang berjudul "Upaya mengatasi pelanggaran tata tertib sekolah melalui efektifitas konseling individu dengan teknik Rasional Emotif Behavior pada siswa kelas XI IPS 2 SMA Negeri 2 Pacitan tahun pelajaran 2019/2020.

Rumusan masalah penelitian tindakan kelas ini adalah apakah efektifitas konseling individual dengan teknik Rational Emotif Behavior dalam mengatasi siswa yang melanggar tata tertib sekolah di kelas XI IPS 2 SMA Negeri 2 Pacitan tahun pelajaran 2019/2020

Tujuan dari penelitian tindakan kelas ini adalah Untuk mengetahui efektifitas konseling individu dengan teknik konseling Rational Emotif Behavior dalam mengatasi siswa yang melanggar tata tertib sekolah di kelas XI IPS 2 SMA Negeri 2 Pacitan tahun pelajaran 2019/2020

\section{METODOLOGI PENELITIAN}

Penelitian ini menggunakan populasi para siswa SMA Negeri 2 Pacitan kelas XI IPS 2 sejumlah 26 siswa yang ditentukan 
Jurnal HELPER, Vol 37 No 2 (2020) 38 - 47

Bimbingan dan Konseling Universitas PGRI Adi Buana Surabaya

ISSN: 02162938

dengan cara random kelas (Sumadi Suryabrata, 2018). Prosedur yang peneliti lakukan dalam mengunakan random kelas yaitu, pertama membuat undian cluster yang berisi kelas XI IPS 1 sampai undian cluster XI IPS 2. Selanjutnya empat undian tersebut di acak dan diambil satu undian. Ternyata undian yang didapatkan adalah XI IPS 2 dengan demikian kelas XI IPS 2 ditentukan sebagai populasi penelitian. Penelitian ini mengambil sampel dengan menggunakan teknik purposive sampling yaitu menentukan sampel dari populasi dengan menentukan kriteria dengan karakter sampel yaitu para siswa SMA Negeri 2 Pacitan kelas XI IPS 2 yang melanggar tata tertib.

Teknik pengumpulan data dengan inventori selama dua tahap, yaitu tes inventori tahap I, tahap II. Hasil tes ini digunakan untuk mengukur persentase tingkat terisolirnya siswa di kelas.

Kisi-kisi instrument yang dipakai dalam penelitian tindakan kelas

\begin{tabular}{|c|c|c|c|c|c|c|}
\hline \multirow{2}{*}{\begin{tabular}{|c}
$\begin{array}{c}\text { Varia } \\
\text { bel }\end{array}$ \\
\\
Sicwa
\end{tabular}} & \multirow{2}{*}{$\begin{array}{c}\text { Sub } \\
\text { variabel }\end{array}$} & \multicolumn{2}{|c|}{ Indikator } & \multicolumn{2}{|c|}{ No.item } & $\begin{array}{l}\mathbf{J} \\
\mathbf{m}\end{array}$ \\
\hline & & & & $(+)$ & $(-)$ & \\
\hline \multirow{2}{*}{$\begin{array}{l}\text { Siswa } \\
\text { yang } \\
\text { melan } \\
\text { ggarta } \\
\text { ta } \\
\text { tertib. }\end{array}$} & \multirow[t]{2}{*}{$\begin{array}{l}\text { Menghor } \\
\text { mati. }\end{array}$} & & $\begin{array}{l}\text { Menghor } \\
\text { mati } \\
\text { guru. }\end{array}$ & 1,2 & 4 & 3 \\
\hline & & 2) & $\begin{array}{l}\text { Menghar } \\
\text { gai } \\
\text { karyawa } \\
\text { n/karya } \\
\text { wati }\end{array}$ & 4,5 & 6 & 3 \\
\hline
\end{tabular}

\begin{tabular}{|c|c|c|c|c|}
\hline $\begin{array}{l}\text { Menjaga } \\
\text { nama baik }\end{array}$ & \begin{tabular}{|l} 
Dapat \\
memberikan \\
prestasi \\
sekolah
\end{tabular} & & 7 & 1 \\
\hline $\begin{array}{l}\text { Ikut } \\
\text { bertanggu } \\
\text { ng jawab } \\
\text { atau } \\
\text { terwujudn } \\
\text { ya sekolah } \\
\text { yang baik. }\end{array}$ & $\begin{array}{l}\text { Berperandal } \\
\text { amorganisas } \\
\text { i }\end{array}$ & 8,9 & $\begin{array}{l}10, \\
11\end{array}$ & 4 \\
\hline $\begin{array}{l}\text { Mengikuti } \\
\text { pelajaran } \\
\text { dengan }\end{array}$ & $\begin{array}{ll}\text { 1) } & \text { Tidak } \\
& \text { membua } \\
\text { t gaduh }\end{array}$ & 12 & $\begin{array}{l}13, \\
14, \\
15\end{array}$ & 4 \\
\hline tertib & $\begin{array}{ll}\text { 2) } & \text { Mengan } \\
& \text { ggu } \\
\text { jalannya } \\
\text { pelajaran }\end{array}$ & $\begin{array}{l}16,1 \\
7\end{array}$ & $\begin{array}{l}18, \\
19\end{array}$ & 4 \\
\hline $\begin{array}{l}\text { Mengikuti } \\
\text { sekurang- } \\
\text { kurangnya } \\
\text { kegiatan } \\
\text { ekstrakuli } \\
\text { kuler dan } \\
\text { pengemba } \\
\text { ngan diri }\end{array}$ & $\begin{array}{l}\text { Aktif dalam } \\
\text { ekstrakuliku } \\
\text { ler }\end{array}$ & 20 , & $\begin{array}{l}21, \\
22\end{array}$ & 3 \\
\hline $\begin{array}{l}\text { Memakai } \\
\text { seragam } \\
\text { sekolah } \\
\text { dengan } \\
\text { ketentuan } \\
\text { yang } \\
\text { ditetapkan } \\
\text { sekolah }\end{array}$ & $\begin{array}{l}\text { Memakai } \\
\text { atribut } \\
\text { sesuai } \\
\text { dengan } \\
\text { ketentuan }\end{array}$ & & $\begin{array}{l}23, \\
24, \\
25\end{array}$ & 3 \\
\hline Mengikuti & Mengikuti & 26 & 27 & 3 \\
\hline
\end{tabular}


Jurnal HELPER, Vol 37 No 2 (2020) 38 - 47

Bimbingan dan Konseling Universitas PGRI Adi Buana Surabaya

ISSN: 02162938

\begin{tabular}{|c|c|c|c|c|c|}
\hline & $\begin{array}{l}\text { upacara } \\
\text { bendera. }\end{array}$ & $\begin{array}{l}\text { upacara } \\
\text { dengan } \\
\text { hikmah. }\end{array}$ & & 28 & \\
\hline & $\begin{array}{l}\text { Mengikuti } \\
\text { kegiatan } \\
\text { keagamaa } \\
\text { n }\end{array}$ & $\begin{array}{l}\text { Mengikuti } \\
\text { pondok } \\
\text { romadhon } \\
\text { atau } \\
\text { kegiatan } \\
\text { keagamaan } \\
\text { lainnya. }\end{array}$ & & 29 & 1 \\
\hline & $\begin{array}{l}\text { Ikut serta } \\
\text { memelihar } \\
\text { a sarana } \\
\text { dan } \\
\text { prasarana } \\
\text { sekolah }\end{array}$ & $\begin{array}{l}\text { Tidak } \\
\text { merusak } \\
\text { fasilitas } \\
\text { sekolah }\end{array}$ & $\begin{array}{l}30,3 \\
1,32\end{array}$ & $\begin{array}{l}33, \\
34\end{array}$ & 5 \\
\hline & $\begin{array}{l}\text { Melaksana } \\
\text { kan dan } \\
\text { melestarik } \\
\text { an } 7 \mathrm{~K}\end{array}$ & $\begin{array}{l}\text { Saling } \\
\text { menjaga } \\
\text { kerukunan } \\
\text { siswa }\end{array}$ & $\begin{array}{l}35,3 \\
6\end{array}$ & 37 & 3 \\
\hline & $\begin{array}{l}\text { Melengka } \\
\text { pi segala } \\
\text { keperluan } \\
\text { peralatan } \\
\text { sekolah }\end{array}$ & $\begin{array}{l}\text { Membawa } \\
\text { peralatan } \\
\text { sekolah }\end{array}$ & $\begin{array}{l}38,3 \\
9\end{array}$ & & 2 \\
\hline & $\begin{array}{l}\text { Melaksana } \\
\text { kan tugas- } \\
\text { tugas dari } \\
\text { guru } \\
\text { berkaitan } \\
\text { dengan } \\
\text { proses } \\
\text { belajar }\end{array}$ & $\begin{array}{l}\text { Mengerjaka } \\
\text { n PR }\end{array}$ & & 40 & 1 \\
\hline Jumla & & & & & 4 \\
\hline
\end{tabular}

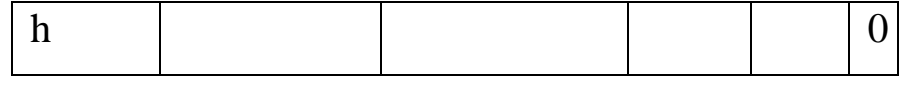

Dalam penelitian ini metode analisis data yang digunakan adalah Analisis Deskriptif Presentase. Metode ini digunakan untuk mengkaji variabel yang ada pada penelitian ini yaitu Konseling Individu Teknik Rational Emotif Behavior dan siswa yang melanggar tata tertib sekolah.

\section{Prosentase Hasil Tes Siswa Kelas XI IPS}

\section{2 pada siklus 1}

\begin{tabular}{|l|l|l|}
\hline Klien & Prosentase & Kriteria \\
\hline AA & $53 \%$ & Rendah \\
\hline BS & $55 \%$ & Rendah \\
\hline DK & $76 \%$ & Sedang \\
\hline EP & $77 \%$ & Tinggi \\
\hline JP & $54 \%$ & Sedang \\
\hline MA & $52,5 \%$ & Rendah \\
\hline NR & $77,5 \%$ & Tinggi \\
\hline RD & $54,5 \%$ & Rendah \\
\hline RN & $38 \%$ & Rendah \\
\hline SW & $44 \%$ & Rendah \\
\hline
\end{tabular}

Berdasarkan perhitungan prosentase dapat disimpulkan bahwa prosentase siswa yang melanggar tata tertib sekolah dari 10 anak/klien pada siklus 1 terdapat 6 siswa mendapat prosentase $60 \%$ yang masuk dalam kriteria rendah, kriteria sedang 2 siswa atau $20 \%$ sedangkan 2 siswa atau 60 $\%$ kriteria baik.

Rendahnya prosentase tes pertama pada siklus 1 layanan konseling individu teknik Rational Emotif Behavior dapat dimaknai bahwa faktor yang menyebabkan siswa 
Jurnal HELPER, Vol 37 No 2 (2020) 38 - 47

Bimbingan dan Konseling Universitas PGRI Adi Buana Surabaya

ISSN: 02162938

melanggar tata tertib sekolah meliputi siswa memanjangkan rambut, berkata jorok kepada temannya saat diejek, tidak mengerjakan PR, dan bermain kartu remi di kelas itu tinggi.

\section{Prosentase Hasil Tes Siswa Kelas XI IPS 2 pada}

\section{Siklus 2}

\begin{tabular}{|l|l|l|}
\hline Klien & Prosentase & Kriteria \\
\hline AA & $76 \%$ & Sedang \\
\hline BS & $75 \%$ & Sedang \\
\hline DK & $86 \%$ & Tinggi \\
\hline EP & $80 \%$ & Tinggi \\
\hline JP & $84 \%$ & Tinggi \\
\hline MA & $77 \%$ & Tinggi \\
\hline NR & $83 \%$ & Tinggi \\
\hline RD & $80 \%$ & Tinggi \\
\hline RN & $78 \%$ & Tinggi \\
\hline SW & $77 \%$ & Tinggi \\
\hline
\end{tabular}

Berdasarkan perhitungan hasil siklus 2 maka dapat disimpulkan bahwa keadaan siswa melanggar tata tertib sekolah Kelas X TKJ-1 SMK Negeri Pringkuku setelah pada siklus 2 layanan konseling individu diperoleh prosentase $80,00 \%$ atau 8 siswa yang masuk dalam kriteria tinggi, sedangkan prosentase sedang 2 siswa atau $20 \%$.

Sesuai dengan rumusan masalah dalam penelitian ini, akan dipaparkan perubahan prosentase siswa yang melanggar tata tertib sekolah sebelum dan sesudah dilakukan Konseling Teknik Rational Emotif Behavior. Berikut perbedaan antara tes pertama (Siklus 1) dan tes kedua (Siklus 2) siswa yang melanggar tata tertib sekolah.

Perbedaan prosentase siswa yang melanggar tata tertib sekolah sebelum dan setelah mengikuti Konseling teknik Rational Emotif Behavior, hal ini dilakukan dengan tahapan yang sesuai gambaran masalah siswa yang melangagar tata tertib sekolah setelah memperoleh layanan konseling individu teknik rational emotif behavior dan sekaligus mengetahui perbandingan siswa yang melanggar tata tertib sekolah antara sebelum dan sesudah memperoleh layanan konseling individu teknik rational emotif behavior.

Adapun hasil dari kegiatan siklus 1 dan siklus 2 dapat diketahui pada kagiatan tersebut sesuai dengan tujuan penelitian ini yaitu untuk mengetahui deskripsi siswa yang melanggar tata tertib sekolah pada siklus 1 teknik rational emotif behavior maupun siklus 2 adalah sebagai berikut:

\begin{tabular}{|c|c|c|c|c|c|}
\hline \multirow{2}{*}{$\begin{array}{l}\mathbf{N} \\
\mathbf{O}\end{array}$} & \multirow{2}{*}{$\begin{array}{c}\text { Klie } \\
\mathbf{n}\end{array}$} & \multicolumn{2}{|c|}{ Siklus 1} & \multicolumn{2}{|c|}{ Siklus 2} \\
\hline & & $\begin{array}{l}\text { Prose } \\
\text { ntase }\end{array}$ & $\begin{array}{c}\text { Krite } \\
\text { ria }\end{array}$ & $\begin{array}{l}\text { Prose } \\
\text { ntase }\end{array}$ & Kriteria \\
\hline 1 & AA & $53 \%$ & $\begin{array}{c}\text { Renda } \\
\mathrm{h}\end{array}$ & $76 \%$ & Sedang \\
\hline 2 & $\mathrm{BS}$ & $55 \%$ & $\begin{array}{c}\text { Renda } \\
\mathrm{h}\end{array}$ & $75 \%$ & Sedang \\
\hline 3 & DK & $76 \%$ & $\begin{array}{c}\text { Sedan } \\
\mathrm{g}\end{array}$ & $86 \%$ & Tinggi \\
\hline 4 & $\mathrm{EP}$ & $77 \%$ & $\begin{array}{c}\text { Tingg } \\
\text { i }\end{array}$ & $80 \%$ & Tinggi \\
\hline 5 & JP & $54 \%$ & $\begin{array}{c}\text { Sedan } \\
\mathrm{g}\end{array}$ & $84 \%$ & Tinggi \\
\hline 6 & MA & $\begin{array}{c}52,5 \\
\%\end{array}$ & $\begin{array}{c}\text { Renda } \\
\mathrm{h}\end{array}$ & $77 \%$ & Tinggi \\
\hline 7 & NR & $\begin{array}{c}77,5 \\
\%\end{array}$ & $\begin{array}{c}\text { Tingg } \\
\text { i }\end{array}$ & $83 \%$ & Tinggi \\
\hline 8 & $\mathrm{RD}$ & $\begin{array}{c}54,5 \\
\%\end{array}$ & $\begin{array}{c}\text { Renda } \\
\qquad \mathrm{h}\end{array}$ & $80 \%$ & Tinggi \\
\hline
\end{tabular}


Jurnal HELPER, Vol 37 No 2 (2020) 38 - 47

Bimbingan dan Konseling Universitas PGRI Adi Buana Surabaya

\begin{tabular}{|c|c|c|c|c|c|}
\hline 9 & RN & $38 \%$ & $\begin{array}{c}\text { Renda } \\
\mathrm{h}\end{array}$ & $78 \%$ & Tinggi \\
\hline 10 & SW & $44 \%$ & $\begin{array}{c}\text { Renda } \\
\mathrm{h}\end{array}$ & $77 \%$ & Tinggi \\
\hline
\end{tabular}

Perbedaan siswa yang melanggar tatatertib sekolah pada siklus 1 dan siklus 2 dalam mengikuti Konseling Individu Teknik Rational Emotif Behavior lebih jelasnya dapat dilihat pada

\section{Prosentase pelanggaran tata tertib}

10 siswa yang dilakukan pada siklus 1 dan siklus 2

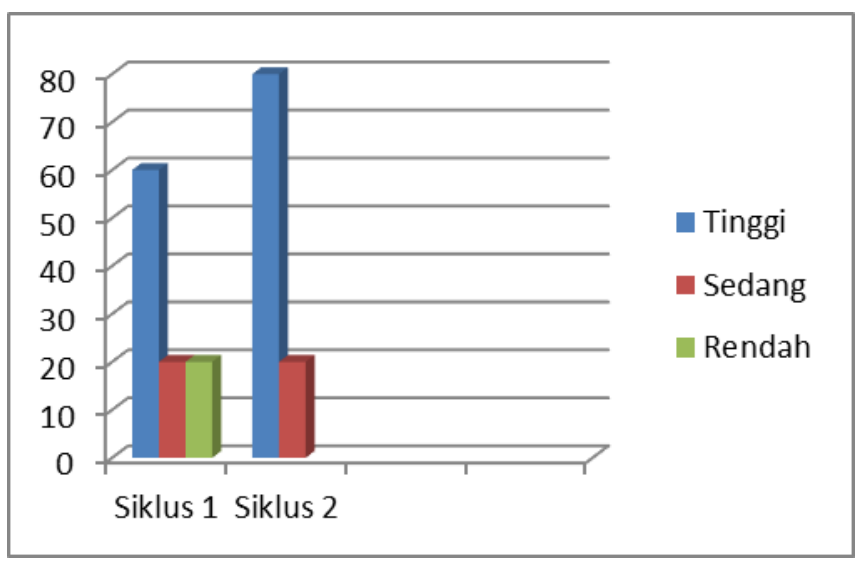

Berdasarkan tabel dan grafik diketahui bahwa Subyek Penelitian mengalami kenaikan presentase siswa melanggar tata tertib sekolah yang cukup signifikan. Hal ini terlihat dari perbandingan antara hasil tes siklus 1 dan tes siklus 2. Prosentase siswa yang melanggar tata tertib sekolah pada siklus 1 adalah $60 \%$ dan masuk dalam criteria rendah. Sedangkan prosentase Siswa yang melanggar tata tertib sekolah siklus 2 adalah $80 \%$ dan masuk dalam criteria tinggi. Secara keseluruhan kenaikan Siswa yang melanggar tata tertib sekolah pada siklus 1 ke siklus 2 yaitu 20\%. Semakin tinggi skor yang diperoleh maka, semakin rendah perilaku melanggar tata tertib sekolah yang dilakukan oleh 10 siswa/klien.

\section{PEMBAHASAN}

Pada siklus 1 Konseling Individu Teknik Rational Emotif Behavior siswa yang melanggar tata tertib sekolah di beri tes terlebih dahulu dengan hasil prosentase sebesar $60 \%$ dan hasil tersebut masih rendah. Hukuman dan disiplin sekolah adalah" tidak terlaksananya peraturan atau tata tertib secara konsisten akan menjadi salah satu penyebab utama terjadinya berbagai bentuk dan kenakalan yang dilakukan siswa, baik di didalam maupun di luar sekolah".

Berdasarkan pengertian di atas, dapat disimpulkan bahwa pelanggaran adalah bentuk kenakalan siswa yang dilakukan menurut kehendaknya sendiri tanpa menghiraukan peraturan yang telah dibuat.

Jenis peraturan yang ditetapkan oleh sekolah meliputi :

a. Menghormati

b. Menjaga nama baik

c. Ikut bertanggung jawab atau terwujudnya sekolah

d. Mengikuti pelajaran dengan tertib

e. Mengikuti sekurang - kurangnya kegiatan ekstrakulikuler dan pengembangan diri

f. Memakai seragam sekolah dengan ketentuan yang ditetapkan sekolah

g. Mengikuti upacara bendera.

h. Mengikuti kegiatan keagamaan 
i. Ikut serta memelihara sarana dan prasarana sekolah

j. Melaksanakan dan melestarikan $7 \mathrm{~K}$

k. Melengkapi segala keperluan peralatan sekolah

1. Melaksanakan tugas-tugas dari guru berkaitan dengan proses belajar

Hal tersebut sama dengan yang dialami oleh 10 siswa tersebut dimana 10 siswa kelas XI IPS 2 SMA Negeri 2 Pacitan telah melakukan bentuk kenakalan siswa yang dilakukan menurut kehendaknya sendiri tanpa menghiraukan peraturan yang telah dibuat. Setelah diberi tes pertama pada siklus 1 seperti yang disebutkan diatas, kemudian dari 10 siswa tersebut diberi layanan konseling individu teknik rational emotif behavior. Setelah diberi layanan kemudian 10 siswa tersebut diberi tes kedua pada siklus 2 untuk mengetahui berhasil atau tidaknya layanan konseling dengan teknik Rational Emotif Behavior.

Hasil tes kedua teknik konseling yang telah diberikan kepada 10 siswa tersebut mengalami sedikit perubahan yaitu $80 \%$. Hal ini menunjukkan bahwa ada peningkatan kearah positif. Meskipun selisih hasil tes pertama dan kedua hanya $20 \%$ namun perubahan tersebut dapat dilihat pada keadaan yang sesungguhnya. Pada pertemuan pertama rambut klien panjang dan tidak dirapikan, berkata jorok kepada teman-temannya yang mengejeknya, menyontek PR teman dan main kartu remi di dalam kelas. Namun setelah diberikan perlakuan perilaku klien berubah menjadi baik, dari sebagian siswa sudah merapikan rambutnya. Sudah tidak menyontek PR temannya, tidak berkata jorok kepada teman yang megejeknya bahkan tidak mengulangi bermain kartu Remi di dalam kelas.
Sesuai dengan judul diatas yaitu "Upaya mengatasi pelanggaran tata tertib sekolah melalui konseling individu dengan teknik Rasional Emotif Behavior pada siswa kelas XI IPS 2 SMA Negeri 2 Pacitan tahun pelajaran 2019/2020" dapat disimpulkan bahwa layanan konseling teknik rational emotif behavior bisa dikatakan efektif untuk menangani siswa yang melanggar tata tertib sekolah. Hal itu dapat dibuktikan dengan prosentasi pada siklus 1 sebesar $60 \%$ dan pada siklus 2 sebesar $80 \%$. Terdapat keterangan bahwa Semakin tinggi skor yang diperoleh maka, semakin rendah perilaku melanggar tata tertib sekolah yang dilakukan disekolah.

\section{KESIMPULAN DAN SARAN}

Berdasarkan uraian diatas dapat disimpulkan bahwa konseling individu melalui teknik rational emotif behavior dapat mengatasi siswa yang melanggar tata tertib sekolah pada siswa kelas XI IPS 2 SMA Negeri 2 Pacitan tahun pelajaran 2019/2020

Hal ini terbukti dari hasil Penelitian Tindakan Kelas (PTK), diperoleh hasil tes inventori setelah konseling individu melalui teknik rational emotif behavior pada 10 siswa yang dilakukan sebagai klien sebagai berikut.

1. Pada siklus I

a) Persentase 10 siswa dalam melakukan pelanggaran tata tertib sekolah sebesar $60 \%$

b) Termasuk kriteria tinggi

2. Pada siklus II 
a) Persentase 10 siswa dalam melakukan pelanggaran tata tertib sekolah sebesar $80 \%$

b) Termasuk kriteria rendah

Konseling Individu dengan Teknik Rational Emotif Behavior efektif untuk membantu siswa yang melakukan pelanggaran tata tertib yang dilakukan pada 10 siswa kelas XI IPS 2 SMA Negeri 2 Pacitan tahun pelajaran 2019/2020 disebabkan adanya peningkatan antara hasil siklus 1 sebelum diadakan konseling individu yaitu sebesar $80 \%$ dan hasil siklus 2 setelah diadakan konseling individu sebesar 60\%. Hal ini menunjukkan bahwa ada peningkatan kearah positif. Meskipun selisih hasil tes pertama dan kedua hanya 20\%. Terdapat keterangan bahwa Semakin tinggi skor yang diperoleh maka, semakin rendah perilaku melanggar tata tertib sekolah yang dilakukan oleh siswa 10 siswa/klien yang dijadikan observasi secara langsung yang dilakukan di kelas.

Dari hasil penelitian serta kesimpulan di atas, peneliti dapat menyampaikan saran-saran sebagai berikut :

1. Bagi Rekan konselor

Konselor harus lebih memperhatikan siswa dan memberikan perhatian serta memberikan layanan konseling individual bagi siswa yang melanggar tata tertib sekolah.

\section{Bagi Guru Mata Pelajaran}

Hendaknya guru mata pelajaran melakukan pendekatan terhadap siswa terutama yang melanggar tata tertib seoklah agar diketahui sebab terjadinya masalah yang menyebabkan siswa tidak mematuhi tata tertib yang ada di sekolah sehingga akan lebih menunjang kegiatan siswa dalam menerima pelajaran serta menciptakan suasana nyaman selama proses kegiatan belajar mengajar serta diharapkan siswa akan patuh dan tertib di lingkungan sekolah maupun luar sekolah .

3. Bagi Sekolah

Hasil penelitian tindakan kelas menunjukkan bahwa pelaksanaan konseling teknik Rational Emotif Behavior yang dilaksanakan berjalan efektif dalam mengatasi siswa yang melanggar tata tertib sekolah dari 10 siswa ini, maka dari itu semoga dapat berguna untuk menjadi pembelajaran untuk menghadapi siswa lain yang melanggar tata tertib.

\section{DAFTAR RUJUKAN}

Arikunto, Suharsimi. 2010. Prosedur penelitian dan praktik. Jakarta :Rineka Cipta.

Corey, Gerald. 2007. Teori dan praktek konseling dan psikoterapi. Bandung :refikaaditama.

Departemen Pendidikan dan Kebudayaan.1988

.KamusBesarBahasa Indonesia. Jakarta

Hurlock, Elizabeth. 2005. Perkembangan Anak Jilid I . Meitasari \& Zarkasih, penerjemah. Jakarta: Erlangga..

Kartono, Kartini dan Gulo, Dali. 2000. Kamus Psikologi. Bandung: CV. Pioner Jaya.

Prayitno. Layanan Konseling Perorangan. FIP Universitas Negeri Padang: Padang 2005. 
Jurnal HELPER, Vol 37 No 2 (2020) 38 - 47

Bimbingan dan Konseling Universitas PGRI Adi Buana Surabaya

ISSN: 02162938

Sunanto, Juang. 2005. Pengantar penelitian dengan subjek tunggal. Universitas Pendidikan Indonesia.

Sukardi, Dewa Ketut.

2008. Pengantar Pelaksanaan Program Bimbingan dan Konseling di Sekolah. Jakarta: Rineka Cipta

Winkel, W.S. 2007. Bimbingan dan Konseling di Institut Pendidikan. Jakarta : PT. Gramedia. 